\title{
Mechanical properties of geomaterials made of steelmaking slag mixed with fibrous wood chips or chemical fibers
}

\author{
Akihiro Oshino ${ }^{\text {i) }}$, Yoshiaki Kikuchi ii), Shohei Noda ${ }^{\text {iii), }}$ \\ Tomotaka Yoshikawa ${ }^{\text {iv) }}$, Taiki Sugihara ${ }^{\text {v)}}$, and Tomotaka Watanabe ${ }^{\text {v) }}$
}

i) Graduate Student, Department of Civil Engineering, Tokyo University of Science, 2641, Yamazaki, Noda, Chiba 278-8510, Japan. ii) Professor, Department of Civil Engineering, Tokyo University of Science, 2641, Yamazaki, Noda, Chiba 278-8510, Japan. iii) Assistant Professor, Department of Civil Engineering, Tokyo University of Science, 2641, Yamazaki, Noda, Chiba 278-8510, Japan. iv) Doctoral Candidate, Department of Civil Engineering, Tokyo University of Science, 2641, Yamazaki, Noda, Chiba 278-8510, Japan.

v) Undergraduate Student, Department of Civil Engineering, Tokyo University of Science, 2641, Yamazaki, Noda, Chiba 278-8510, Japan.

\begin{abstract}
The purpose of this study is to investigate the effect of the length of the chemical fibers (CF) on the mechanical properties of slag mixed with CF. Furthermore, the effect of the difference between fibrous wood chips (FWC) and CF on mechanical properties is to be examined. In this study, a series of consolidated drained triaxial compression tests were conducted on a material mixed with steelmaking slag and FWC assuming under sieve residue or CF. The chemical fiber length and curing periods were changed in this study. As a result, it was found that $2 \%$ by volume of the CF mixture increased both the shear strength and the residual strength compared to the slag. However, their increases were up to the fiber length of $20 \mathrm{~mm}$. When $5 \%$ by volume of FWC, the length of which was about $18.9 \mathrm{~mm}$, were mixed to the slag, there were no increases observed in both the shear strength and the residual strength.
\end{abstract}

Keywords: steelmaking slag, fibrous wood chips, chemical fibers, geomaterial, mechanical properties

\section{INTRODUCTION}

Under sieve residue is obtained by separating from disaster waste. It is a size of $20 \mathrm{~mm}$ or less depending on using a vibrating sieve or a rotary sieve. It includes more than $4 \%$ of wood chips. The type, shape, and mixing ratio of the wood chips contained in the disaster waste vary due to the diversity of disaster waste sorting systems. In March 2011 Great East Japan Earthquake, the under sieve residue was difficult to recycle because the effects of wood chips decay and lack of bearing capacity were unknown. However, it is expected that such waste will be generated in future disasters. Therefore, the proposal of an effective use method is an important issue.

Incidentally, steelmaking slag generated as an industrial byproduct at the time of steel production has hydraulic solidification properties. The authors thought that the abovementioned problems will be solved if it becomes possible to utilize the hydraulic solidification properties of steelmaking slag as a geomaterial by hardening the under sieve residue. Furthermore, the authors think that the geomaterial can contribute to early recovery from disasters and reduce the environmental damage caused by the extraction of geomaterials.

The mechanical properties of a material in which steelmaking slag is mixed with wood chips under sieve residue were studied in previous research (Obayashi et al., 2015; Yoshikawa et al., 2017; Oshino et al., 2019). Among them, even if 5\% by volume of fibrous wood chips (FWC) is mixed with slag [a steelmaking slag and a blast-furnace slag fine powder (BFSFP) mixed at a weight ratio of 96:4], the same shear strength as that of slag is exhibited. A reduction in the deviator stress was found after the shear strength became slower than that of the slag (Oshino et al., 2019). In other words, this experiment result show that mixed slag with FWC provide a reinforcing effect.

Research on short-fiber reinforcement soil has been promoted by various research groups (Mori et al., 2017; Yamanaka et al., 2014). It has been clarified that a reinforcing effect exists even when natural fibers are mixed (Sato et al., 2012; Terai et al., 2017). The FWC used by the authors are uneven in length and diameter. Therefore, it is difficult to evaluate the reinforcing effect quantitatively. However, it is necessary to clarify the reinforcing effect of steelmaking slag mixed with FWC in order to utilize the geomaterials effectively in the future. For this reason, the authors thought if the reinforcing effect could be investigated by varying the length of the chemical fibers (CF).

Therefore, the purpose of this study is to investigate the effect of the length of the CF on the mechanical properties of slag mixed with CF. Furthermore, the effect of the difference between FWC and CF on mechanical 
properties is to be examined. A series of consolidated drained triaxial compression tests (hereinafter referred to as $\mathrm{CD}$ tests) were conducted on a material mixed with steelmaking slag and FWC assuming under sieve residue or $\mathrm{CF}$. The $\mathrm{CF}$ length and curing periods were changed in this study.

\section{EXPERIMENT OUTLINE}

\subsection{Materials}

In this study, four types of materials were used: coconut fibers as FWC $\left(\rho_{\mathrm{s}}=0.53 \mathrm{~g} / \mathrm{cm}^{3}, 100\right.$ samples: average diameter $0.27 \mathrm{~mm}$, average length $18.9 \mathrm{~mm}$ ), CF cut into four lengths of nylon wig $\left(\rho_{\mathrm{s}}=1.14 \mathrm{~g} / \mathrm{cm}^{3}\right.$, diameters $0.08 \mathrm{~mm}$, length $5 \mathrm{~mm}, 10 \mathrm{~mm}, 20 \mathrm{~mm}$, and $30 \mathrm{~mm})$, steelmaking slag without aging treatment $\left(\rho_{\mathrm{s}}=\right.$ $3.42 \mathrm{~g} / \mathrm{cm}^{3}, D_{50}=0.85 \mathrm{~mm}$, hereinafter referred to as steelmaking slag), and BFSFP $\left(\rho_{\mathrm{s}}=2.95 \mathrm{~g} / \mathrm{cm}^{3}\right.$, brain value $4000 \mathrm{~cm}^{2} / \mathrm{g}$ ). Ion-exchange water was used for pore water. The BFSFP was mixed for the purpose of promoting and assisting the solidification reaction of steelmaking slag.

Table 1 shows the physical properties of the materials used. Figure 1 shows the images of each sample. Figure 2 shows the grain size distribution curve for the steelmaking slag used in the test.

Table 1. Physical properties of the materials.

\begin{tabular}{|c|c|c|c|}
\hline material & $\begin{array}{c}\text { Density } \\
\rho_{\mathrm{s}}\left(\mathrm{g} / \mathrm{cm}^{3}\right)\end{array}$ & $\begin{array}{c}\text { Fiber length } \\
(\mathrm{mm})\end{array}$ & $\begin{array}{c}\text { Fiber diameter } \\
(\mathrm{mm})\end{array}$ \\
\hline FWC & 0.53 & 18.9 & 0.27 \\
\hline CF & 1.14 & $\begin{array}{c}5,10, \\
20,30\end{array}$ & 0.08 \\
\hline Steelmaking slag & 3.42 & - & - \\
\hline BFSFP & 2.95 & - & - \\
\hline
\end{tabular}

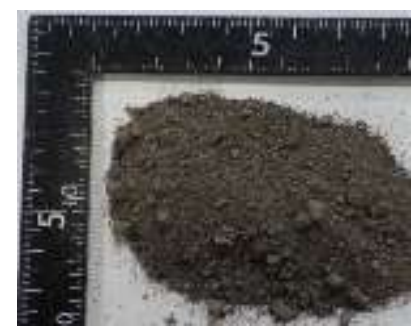

a. Steelmaking slag.

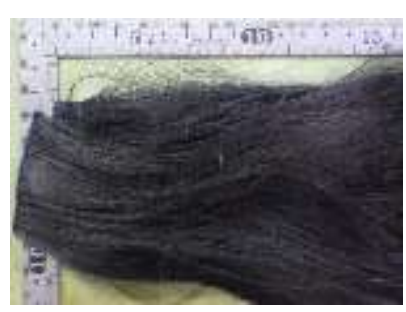

c. CF before cutting.

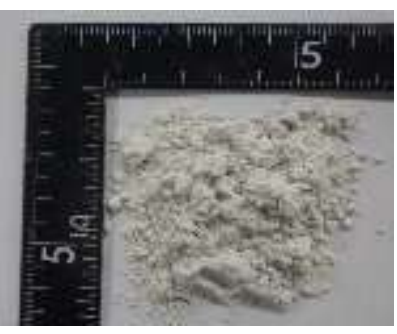

b. BFSFP.

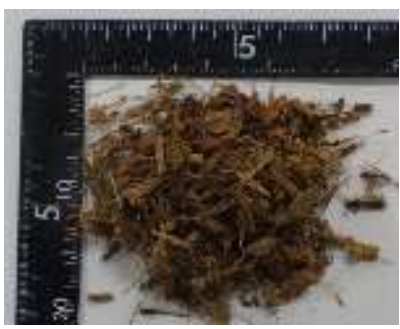

d. Coconut fiber.
Fig. 1. Sample images.

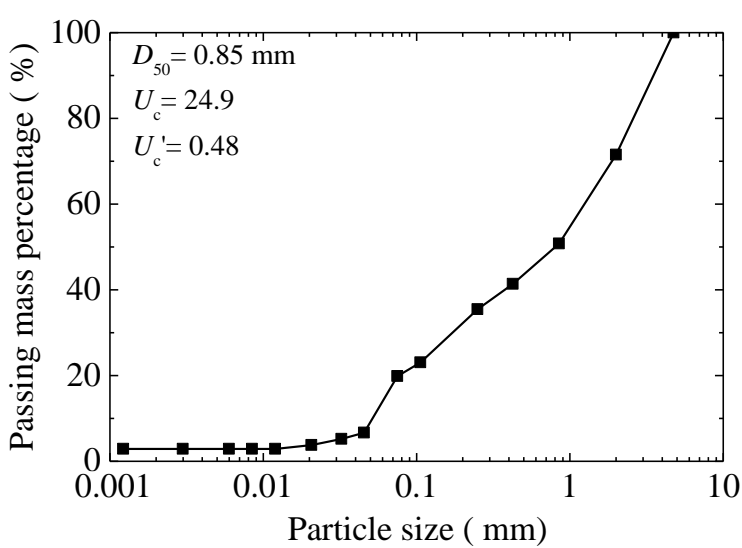

Fig. 2. Grain size distribution curve for steelmaking slag.

\subsection{Specimen preparation method}

Figure 3 shows the results of compaction tests using the mixed materials of coconut fiber $(0 \%, 10 \%$, and $33 \%$ by volume) and slag. The different colors indicate the different content ratios of coconut fiber. The tests were accomplished using the A-b method (JIS A 1210). In all conditions, only one or four samples were tested under each condition. The results of previous studies (Yoshikawa et al., 2017) showed that the dry density of the material mixed with steelmaking slag and wood chips in this particle size range does not significantly change even when the water content is changed. The slag is a mixture of steelmaking slag and BFSFP at a weight ratio of 96:4 (Yoshikawa et al., 2018).

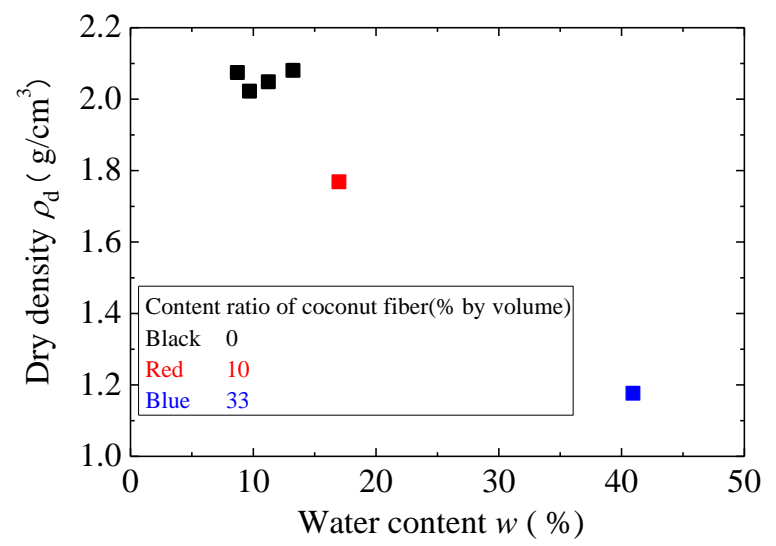

Fig. 3. Compaction test results of slag with different mixing ratios of coconut fibers.

Table 2 shows the specimen conditions that were used to prepare the test samples. The target dry density $\rho_{\mathrm{d}}$ in Table 2 is a value corresponding to the target compaction degree $D_{\mathrm{c}}=95 \%$ based on the maximum dry density obtained from Fig. 3. The target dry density and target water content ratio of $5 \%$ by volume of FWC and $2 \%$ by volume of $\mathrm{CF}$ were calculated by linear interpolation from the test results of 0,10 , and $33 \%$ by volume of coconut fiber. The reason for mixing $2 \%$ by 
volume of $\mathrm{CF}$ is that if $5 \%$ by volume is mixed in the same manner as the mixing ratio of FWC, then the fibers become entangled, resulting in poor mixing with slag and poor workability.

For the specimen, the sample per layer was placed in a bowl and mixed well with a spoon. Then, the specimen was produced by a five-layer compaction method in a plastic mold having a diameter of $50 \mathrm{~mm}$ and a height of $100 \mathrm{~mm}$.

Table 2. Specimen preparation conditions.

\begin{tabular}{|c|c|c|c|c|c|}
\hline Fiber type & $\begin{array}{c}\text { Fiber mixing } \\
\text { ratio } \\
\text { (internally } \% \\
\text { by volume) }\end{array}$ & $\begin{array}{c}\text { Fiber length } \\
(\mathrm{mm})\end{array}$ & $\begin{array}{c}\text { Target dry } \\
\text { density } \\
\rho_{\mathrm{d}}\left(\mathrm{g} / \mathrm{cm}^{3}\right)\end{array}$ & $\begin{array}{c}\text { Target water } \\
\text { content ratio } \\
w(\%)\end{array}$ & $\begin{array}{c}\text { Curing periods } \\
\text { (days) }\end{array}$ \\
\hline -(Slag) & 0 & 0 & 1.98 & 13.3 & \multirow{2}{*}{0} \\
\cline { 1 - 4 } FWC & 5 & 18.9 & 1.83 & 14.6 & 7 \\
CF & 2 & $\begin{array}{c}5,10, \\
20,30\end{array}$ & 1.91 & 15.0 & 28 \\
\hline
\end{tabular}

\subsection{Experimental method}

The authors think that residual strength is affected by fiber and curing. In addition, at higher densities, the shear strength of the drainage condition is lower than that of the undrained condition. Therefore, it was considered necessary to know the mechanical properties of the drainage conditions that are on the dangerous side. For this reason, each specimen was sealed and cured at a constant temperature of $20{ }^{\circ} \mathrm{C}$. CD tests were conducted on the specimens as they reached their prescribed curing duration. In the $\mathrm{CD}$ tests, each specimen was saturated with a back pressure of $200 \mathrm{kPa}$, isotropically consolidated at an effective confining pressure of $50 \mathrm{kPa}$, and compressed under drained conditions at an axial strain rate of $0.01 \% / \mathrm{min}$.

\section{RESULTS AND DISCUSSION}

3.1 Relationship between deviator stress $q$ and axial strain $\varepsilon_{\mathrm{a}}$, and relationship between volumetric strain $\varepsilon_{\mathrm{vol}}$ and axial strain $\varepsilon_{\mathrm{a}}$

Figure 4 shows the relationship between the deviator stress $q$ and axial strain $\varepsilon_{\mathrm{a}}$ according to the difference in the fiber lengths obtained by CD tests for 28 days of curing. The symbols in Fig. 4 show the shear strength $q_{\max }$ and residual strength $q_{\mathrm{r}}$. The different colors of the circle symbols indicate the $\mathrm{CF}$ length. The shear strength of the FWC mixture was lower than that of the slag, unlike the previous results (Oshino et al., 2019). The cause of this result may be that the steelmaking slag used in this study is different from that used in the previous study. When the length of CF was up to $20 \mathrm{~mm}$, the shear strength and the failure strain increased according to the length of CF. However, when the length of CF was 30 $\mathrm{mm}$, the deviator stress strain curve almost overlapped with that of $20 \mathrm{~mm}$.

Figure 5 shows the relationship between the volumetric strain $\varepsilon_{\mathrm{vol}}$ and axial strain $\varepsilon_{\mathrm{a}}$ according to the difference in the fiber lengths obtained by $\mathrm{CD}$ tests for 28 days of curing. The different colors indicate the $\mathrm{CF}$ length. Under all conditions, the volumetric strain indicated a positive dilatancy in which the volume expanded after the volume contraction in the initial stage of shearing.

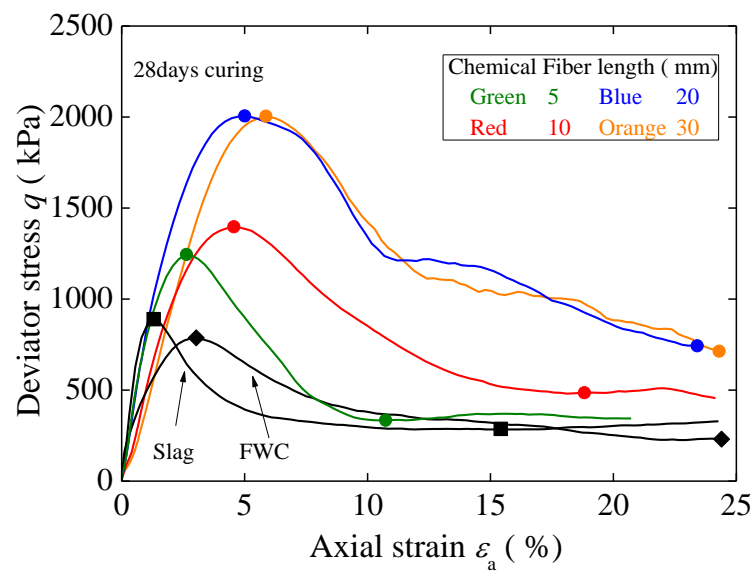

Fig. 4. Relationship between deviator stress $q$ and axial strain $\varepsilon$ a according to difference in fiber length.

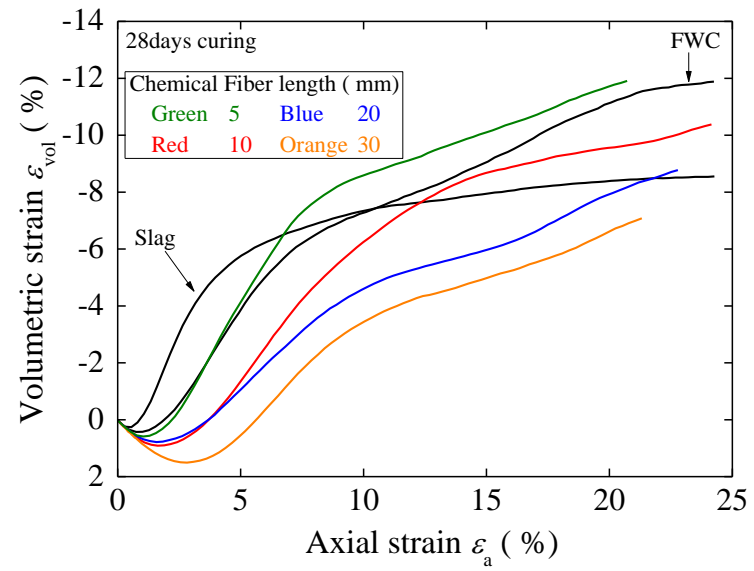

Fig. 5. Relationship between volumetric strain $\varepsilon_{\mathrm{vol}}$ and axial strain $\varepsilon_{a}$ according to difference in fiber length.

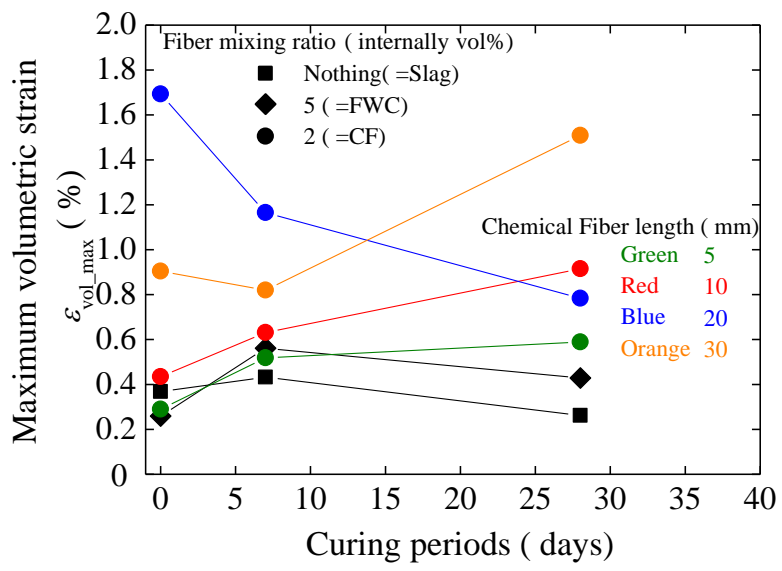

Fig. 6. Relationship between maximum volumetric strain $\varepsilon_{\text {vol_max }}$ and curing periods according to difference in fiber length.

Figure 6 shows the relationship between the 
maximum volumetric strain and curing periods according to the difference in fiber length. The different shapes of the symbols indicate the preparation conditions of the specimen. The different colors of the circle symbols indicate the $\mathrm{CF}$ length. Regardless of the curing periods, when the FWC or CF were mixed, the volume shrinkage tended to be larger than that of the slag. When the CF were mixed, the longer the fibers, the more likely they were to shrink.

\subsection{Effects of fiber length and curing periods on mechanical properties}

Figure 7 shows the relationship between the normalized shear strength $q_{\max } / q_{\text {max_slag_Odays }}$ and the fiber lengths according to the curing periods. The different shapes of the symbols indicate the preparation conditions of the specimen. Normalized shear strength $q_{\text {max }} / q_{\text {max_slag_0days }}$ is the value obtained by dividing the shear strength $q_{\text {max }}$ under the preparation conditions of each specimen by the shear strength $q_{\text {max_slag_0days }}(=639$ $\mathrm{kPa}$ ) of the slag without curing. The shear strength when $2 \%$ by volume of the $\mathrm{CF}$ were mixed was higher than that of the slag, increased linearly up to a fiber length of $20 \mathrm{~mm}$, and showed a value similar to $20 \mathrm{~mm}$ at a fiber length of $30 \mathrm{~mm}$. It means that even the longer fiber makes the shear strength increase, the shear strength reaches to a constant value above a certain fiber length.

The shear strength when $5 \%$ by volume of FWC was mixed was about 0.9 times that of the slag, although the fiber length was $18.9 \mathrm{~mm}$. This indicates that kind of fiber material affects the reinforcing effect to the slag. It is necessary to examine whether maximum reinforcing effect exist when using FWC with different fiber length.

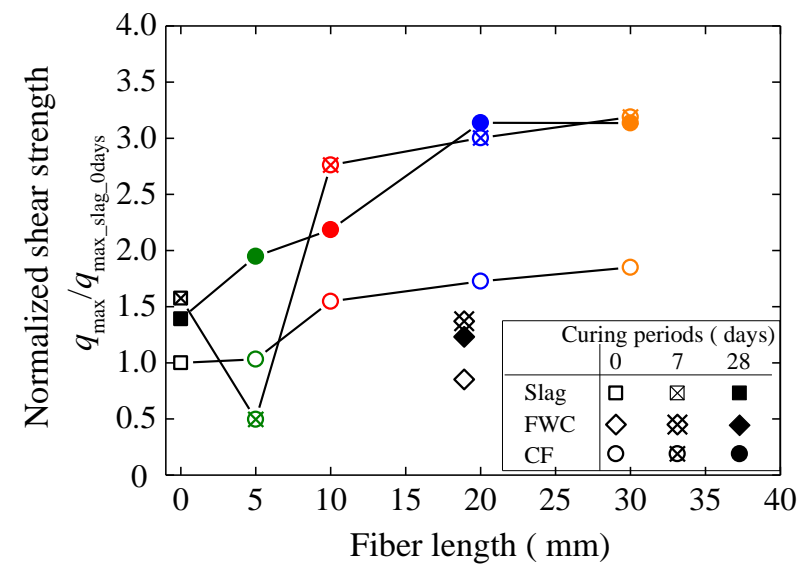

Fig. 7. Relationship between normalized shear strength $q_{\max } /$ $q_{\text {max_slag_Odays }}$ and fiber length according to curing periods.

Figure 8 shows the relationship between the normalized shear strength $q_{\max } / q_{\text {max } \_ \text {slag_0days }}$ and curing periods according to the difference in fiber length. The different shapes of the symbols indicate the preparation conditions of the specimen. Although there is variation from Fig. 8, the shear strength increased by approximately 1.6 times from 0 to 7 days of curing and tended to show the same value from 7 to 28 days of curing.

That is, it is considered that the increase in the shear strength owing to curing is caused by slag rather than by FWC or CF. Under the specimen preparation conditions of this study, even if the FWC or CF were mixed, the shear strength increased as in the case of the slag, and it is considered that the hydration reaction of the slag was not inhibited. The slight change in the shear strength from 7 to 28 days of curing indicates that the slag hydration reaction was almost complete at 7 days of curing. It is unknown what caused the decrease in shear strength from 0 to 7 days of curing with fiber lengths of $5 \mathrm{~mm}$ and from 7 to 28 days of curing with a fiber length of $10 \mathrm{~mm}$ containing $2 \%$ by volume of the CF.

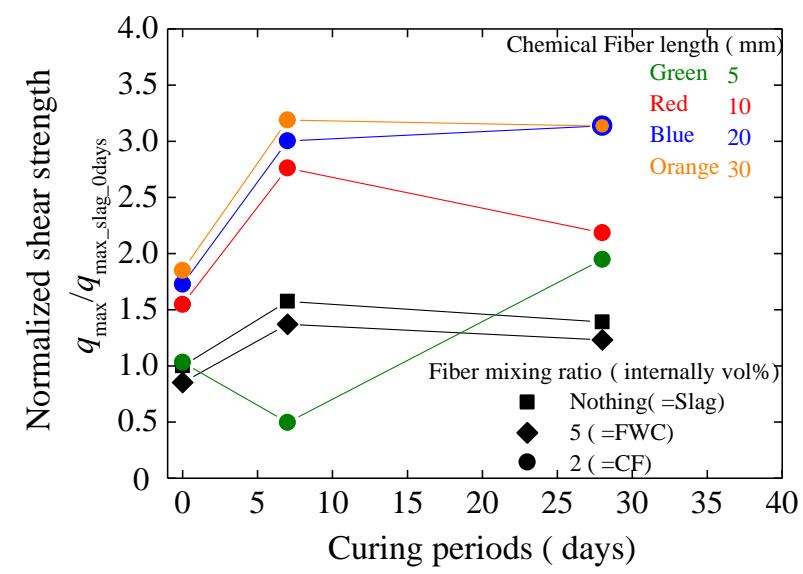

Fig. 8. Relationship between normalized shear strength $q_{\max } /$ $q_{\text {max_slag_Odays }}$ and curing periods according to difference in fiber length.

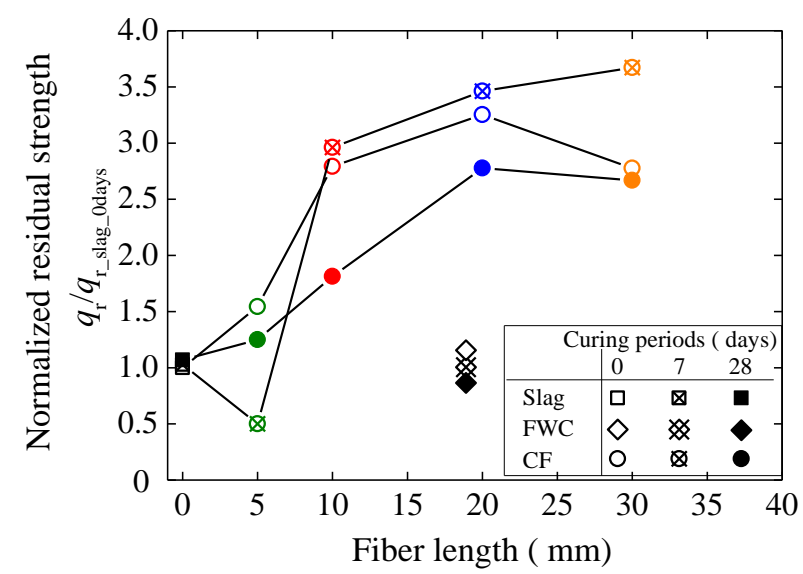

Fig. 9. Relationship between normalized residual strength $q_{\mathrm{r}} /$ $q_{\mathrm{r}_{-} \text {slag_odays }}$ and fiber length according to curing periods.

Figure 9 shows the relationship between the normalized residual strength $q_{\mathrm{r}} / q_{\mathrm{r}_{\text {}} \text { slag_0days }}$ and the fiber length according to the curing periods. The different shapes of the symbols indicate the preparation conditions of the specimen. The normalized residual strength $q_{\mathrm{r}} / q_{\mathrm{r} \_ \text {slag_Odays }}$ is the value obtained by dividing 
the residual strength $q_{\mathrm{r}}$ under the preparation conditions of each specimen by the residual strength $q_{\mathrm{r}_{-} \text {slag_odays }}$ $(=267 \mathrm{kPa})$ of the slag without curing. The residual strength when $2 \%$ by volume of the CF were mixed was higher than that of the slag, increased linearly up to a fiber length of $20 \mathrm{~mm}$, and showed a value similar to 20 $\mathrm{mm}$ at $30 \mathrm{~mm}$. It means that even the longer fiber makes the residual strength increase, the residual strength reaches to a constant value above a certain fiber length.

The residual strength when $5 \%$ by volume of FWC was mixed was about the same as that of the slag, although the fiber length was $18.9 \mathrm{~mm}$. This indicates that the fiber material has a reinforcing effect that increases the residual strength rather than the fiber length.

Figure 10 shows the relationship between the normalized residual strength $q_{\mathrm{r}} / q_{\mathrm{r}_{-} \text {slag__days }}$ and the curing periods according to the difference in fiber length. The different shapes of the symbols indicate the preparation conditions of the specimen. Even if the FWC or CF were mixed, an increase in residual strength owing to curing could not be confirmed.

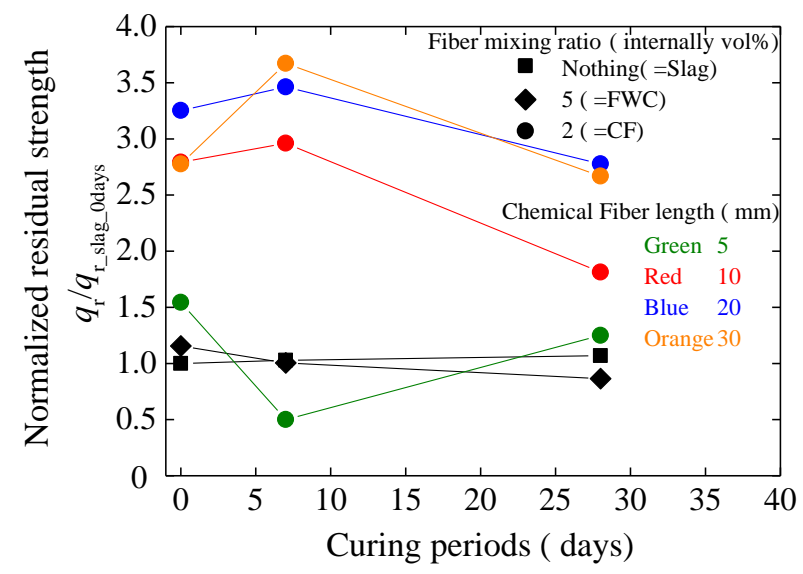

Fig. 10. Relationship between normalized residual strength $q_{\mathrm{r}} /$ $q_{\mathrm{r}_{\text {_slag_}} \text { Odays }}$ and curing periods according to difference in fiber length.

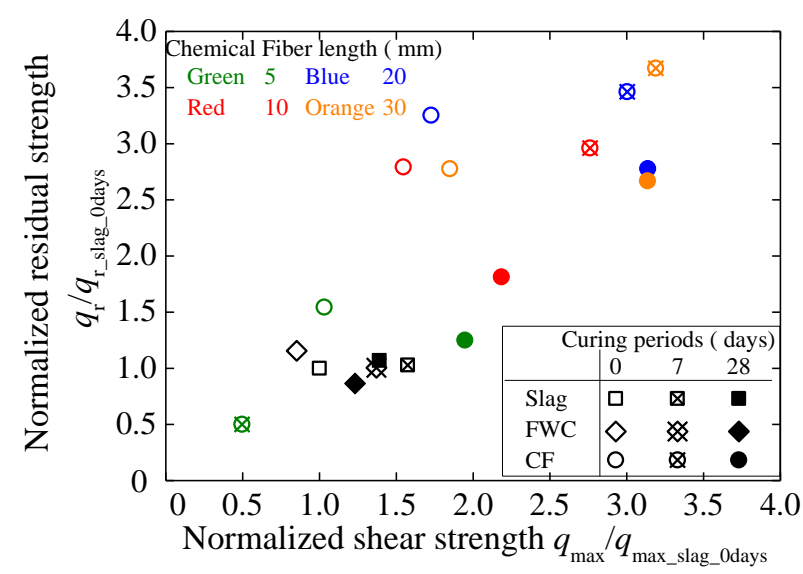

Fig. 11. Relationship between normalized residual strength $q_{\mathrm{r}} /$ $q_{\mathrm{r} \_ \text {slag_Odays }}$ and normalized shear strength $q_{\max } / q_{\text {max _slag_odays. }}$.
Figure 11 shows the relationship between the normalized residual strength $q_{\mathrm{r}} / q_{\mathrm{r}_{-} \text {slag__days }}$ and the normalized shear strength $q_{\text {max }} / q_{\text {max_slag_odays. }}$ The different shapes of the symbols indicate the preparation conditions of the specimen. The normalized shear strength increased with curing. However, the normalized residual strength did not increase. Even if the shear strength is equal, the residual strength changes; therefore, it is difficult to predict the residual strength from the shear strength.

Figure 12 shows the relationship between the failure strain and curing periods according to the difference in fiber length. The different shapes of the symbols indicate the preparation conditions of the specimen. When the fibers such as FWC or CF were mixed, the failure strain became larger than that of only the slag. However, although the length of the FWC was $18.9 \mathrm{~mm}$, the failure strain became lower than the length of the CF of $10 \mathrm{~mm}$ or more. Moreover, regardless of the mixing of the FWC or $\mathrm{CF}$, the failure strain tended to decrease with curing.

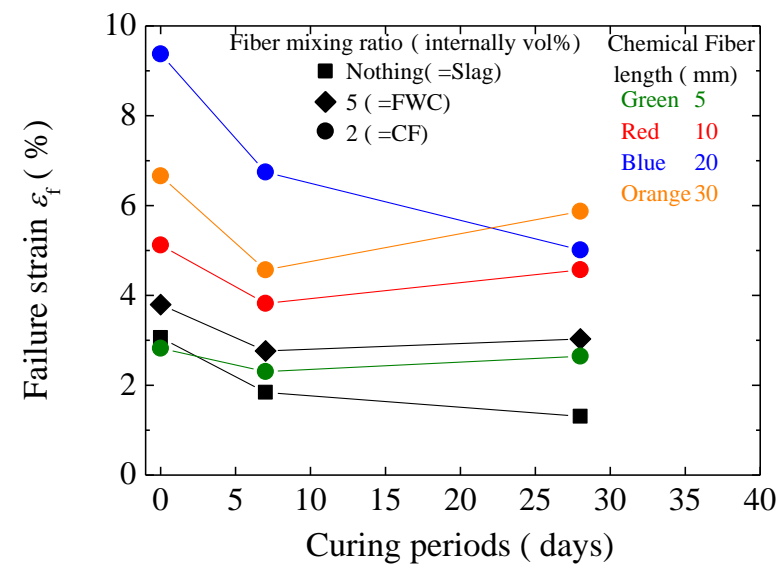

Fig. 12. Relationship between failure strain $\varepsilon_{\mathrm{f}}$ and curing periods according to difference in fiber length.

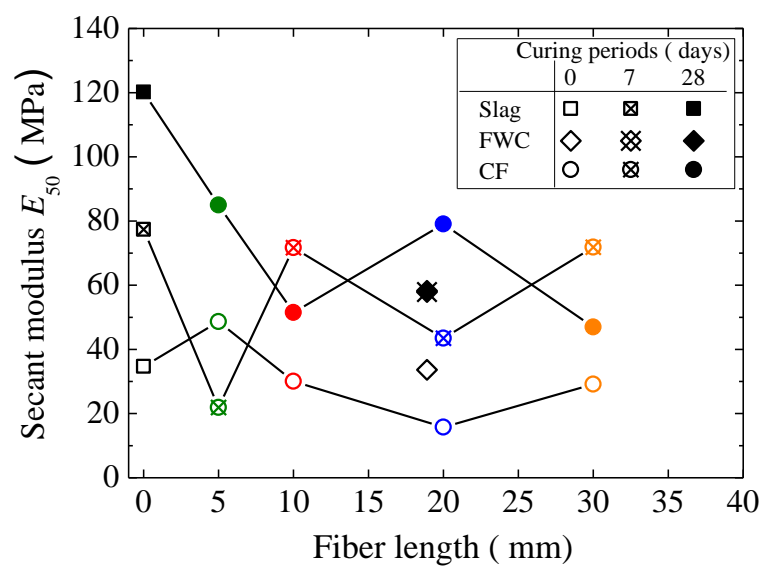

Fig. 13. Relationship between secant modulus $E_{50}$ and fiber length according to curing periods.

Figure 13 shows the relationship between the secant modulus $E_{50}$ and the fiber length according to the curing periods. The different shapes of the symbols indicate the 
preparation conditions of the specimen. The secant modulus $E_{50}(\mathrm{MPa})$ is calculated as follows:

$$
E_{50}=\left(q_{\max } / 2\right) / \varepsilon_{50}
$$

where $\varepsilon_{50}(\%)$ represents the axial strain when the deviator stress has a value of $q_{\max } / 2$. There was no increase in the secant modulus with an increase in the fiber length.

Figure 14 shows the relationship between the secant modulus and curing periods according to the difference in fiber length. The different shapes of the symbols indicate the preparation conditions of the specimen. The secant modulus tended to increase from 0 to 28 days of curing under all conditions. When $5 \%$ by volume of FWC was mixed, the secant modulus did not change from 7 to 28 days of curing.

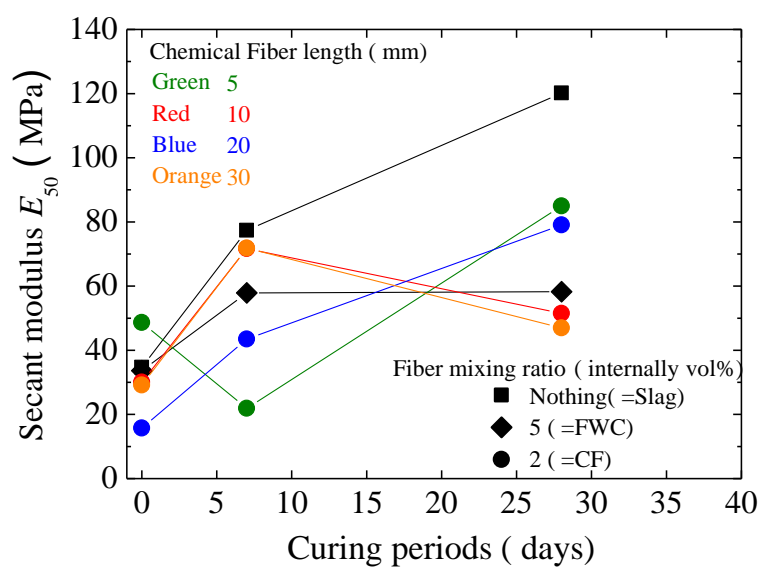

Fig. 14. Relationship between secant modulus $E_{50}$ and curing periods according to difference in fiber length.

From Figures 7, 9, and 12 show that despite the fact that the FWC are about $18.9 \mathrm{~mm}$ long, it did not have the reinforcing effect of increasing the shear strength and residual strength and the failure strain like the CF. This suggests that the material is more important than the length of the fibers in terms of reinforcing effect against shear strength, residual strength and the failure strain.

\section{CONCLUSION}

The purpose of this study is to investigate the effect of the length of the chemical fibers (CF) on the mechanical properties of slag mixed with $\mathrm{CF}$. Furthermore, the effect of the difference between fibrous wood chips (FWC) or CF on mechanical properties is to be examined. CD tests were conducted on a material mixed with steelmaking slag and FWC assuming under sieve residue or $\mathrm{CF}$. The $\mathrm{CF}$ length and curing periods were changed in this experiment. The key findings are as follows:

1) When $2 \%$ by volume of CF are mixed, a fiber reinforcement effect that increases the shear strength, the failure strain, and the residual strength compared to the slag can be confirmed. However, these characteristics increased up to a fiber length of $20 \mathrm{~mm}$ and became constant at $30 \mathrm{~mm}$.

2) The effect of fiber reinforcement when $5 \%$ by volume of FWC increased in the failure strain. However, the effects of increasing the shear strength and the residual strength cannot be confirmed.

3) Regardless of the CF or the FWC mixing, curing decreases the failure strain and does not increase the residual strength.

The reinforcing effects by mixing fibrous material will be affected by many conditions such as friction between fiber and soil, or tensile strength of fibers, and so on. More research is required to clarify these issues.

\section{ACKNOWLEDGEMENTS}

This research was supported by the Steel \& Slag Association and the Obayashi Foundation. The authors express their appreciation for this support.

\section{REFERENCES}

1) Obayashi, S., Kikuchi, Y. and Hyodo, T. (2015): Improvement in strength properties of the geo material by mixing ground steel making slag, Proceedings of The 11th JGS Symposium on Environmental Geotechnics, Fukushima, Japan, 255-260.

2) Yoshikawa, T., Kikuchi, Y., Hyodo, T., Kuroiwa, Y. and Tanaka, Y. (2017): Geomechanical properties as geomaterial of wood chips mixed with steelmaking slag, Proceedings of The 12th JGS Symposium on Environmental Geotechnics, Nagasaki, Japan, 199-204.

3) Yoshikawa, T., Kikuchi, Y., Noda, S., Kakihara, Y., Oshikawa, R. and Oshino A. (2018): Unconfined compression strength of converter steelmaking slag mixed with subsidiary solidifying materials, 15th Geotechnical Society Kanto Branch presentation, Tokyo, Japan, 298-301.

4) Oshino, A., Yoshikawa, T., Oshikawa, R., Kikuchi, Y. and Noda, S. (2019): Geotechnical properties of fibrous wood chips mixed with converter steelmaking slag, 54th Geotechnical Research Presentation, Saitama, Japan, 423424.

5) Mori, K., Hashizume, Y. and Kaneko,K. (2017): Influe nce of the short-fiber mixture ratio on mechanical pro perties of short fiber reinforced sands focusing on den sity of test specimen, Geosynthetics Engineering Journ al, 32, 197-202.

6) Yamanaka, K., Minegishi, K. (2014): Basic mechanical properties of geomaterial mixed with short fibers in cohesive soil, Geosynthetics Engineering Journal, 29, 11-18.

7) Sato, K., Komine, H., Murakami,S., Yasuhara, K. and Kanno, M. (2012): An experimental evaluation on effects of reinforcement by natural fiber mixture material and resistance against seepage failure of various soil material which assumed the Red River Delta, northern Vietnam, Geosynthetics Engineering Journal, 27, 101-108.

8) Terai, M. (2017): Experimental study on properties of strength of natural fiber reinforced materials, Research Reports of the Faculty of Engineering, Kindai University, 51, 41-46. 